\title{
ON-LINE MONITORING APPLICATIONS AT NUCLEAR POWER PLANTS
}

\author{
Ramesh Shankar, and \\ Electric Power Research Institute \\ Eddie Davis, and \\ Edan Engineering \\ Aaron Hussey \\ Electric Power Research Institute
}

\begin{abstract}
On-line monitoring of instrument channels provides increased information about the condition of monitored channels through accurate, more frequent evaluation of each channel's performance over time. This type of performance monitoring is a methodology that offers an alternate approach to traditional time-directed calibration.
\end{abstract}

EPRI's strategic role in on-line monitoring is to facilitate its implementation and cost-effective use in numerous applications at power plants. To this end, EPRI has sponsored an on-line monitoring implementation project at multiple nuclear plants specifically intended to install and use on-line monitoring technology. The selected on-line monitoring method is based on the Multivariate State Estimation Technique. The project has a planned three-year life; seven plants are participating in the project. The goal is to apply on-line monitoring to all types of power plant applications and document all aspects of the implementation process in a series of EPRI deliverables. These deliverables will cover installation, modeling, optimization, and proven cost-benefit.

This paper discusses the actual implementation of on-line monitoring to various nuclear plant instrument systems. A considerable amount of application and development has been completed and the experience gained will be shared in this paper. Examples of detected instrument drift will be provided and modeling issues will be discussed. The uncertainty of different on-line monitoring estimation methods will be discussed. 